\title{
Variabilidade genética estimada entre diplóides de banana por meio de marcadores microssatélites
}

\author{
Edson Perito Amorim (1), Ronaldo Viana dos Reis ${ }^{(2)}$, Janay Almeida dos Santos-Serejo(1), \\ Vanusia Batista de Oliveira Amorim ${ }^{(1)}$ e Sebastião de Oliveira e Silva ${ }^{(1)}$
}

\begin{abstract}
(1)Embrapa Mandioca e Fruticultura Tropical, Caixa Postal 007, CEP 44380-000 Cruz das Almas, BA. E-mail: edson@cnpmf.embrapa.br, janay@cnpmf.embrapa.br, vanusia@cnpmf.embrapa.br, ssilva@cnpmf.embrapa.br (2)Universidade Estadual de Montes Claros, Campus Universitário Professor Darcy Ribeiro, Vila Mauricéia, CEP 39401-089 Montes Claros, MG. E-mail: ronasviana@yahoo.com.br
\end{abstract}

\begin{abstract}
Resumo - O objetivo deste trabalho foi estimar a divergência genética entre 38 diplóides de banana do programa de melhoramento da Embrapa Mandioca e Fruticultura Tropical, incluindo genótipos melhorados, cultivados e selvagens, por meio de 15 marcadores microssatélites ou SSR. As similaridades genéticas, com base no coeficiente de Jaccard, foram utilizadas para fazer o agrupamento dos genótipos pelo método UPGMA. O número de alelos obtidos foi 113, com média de 7,53 alelos por iniciador. A similaridade genética média foi de 0,22 , e variou de 0,028 a 0,48 , o que indica existência de variabilidade genética entre os genótipos. A análise de grupos, com base no polimorfismo de microssatélites, não pôde separar completamente os híbridos melhorados, cultivados e selvagens. Alguns diplóides agruparam-se com base em sua origem geográfica, entre eles Musa ornata e IAC-1, e Tjau Lagada e Lidi, enquanto que, em outros, nenhuma relação foi estabelecida. Houve tendência de agrupamento entre os diplóides aparentados, como: SH3263 e 8694-20, 4279-01 e 9179-03, 1304-06 e 5854-03, 86B79-10 e 7341-03, 86B79-12 e 0337-02, e 9194-04 e 4154-08.
\end{abstract}

Termos para indexação: Musa, diplóides, divergência genética, híbridos, marcadores moleculares.

\section{Genetic variability estimated in banana diploids through microsatellite markers}

\begin{abstract}
The objective of this work was to estimate the genetic diversity between 38 banana diploids from the banana breeding program of Embrapa Mandioca e Fruticultura Tropical (Embrapa Cassava and Tropical Fruits), including improved hybrids, cultivated and wild species, using fifteen SSR markers. Genetic similarities were utilized to cluster genotypes through UPGMA, based on Jaccard coefficient. The average number of alleles per primer was 7.53 , with a total of 113 alleles identified. The average similarity was 0.22 , and ranged from 0.028 to 0.48 , indicating the existence of genetic variability between genotypes. The clustering analysis based on microsatellite polymorphism could not completely separate improved hybrids, cultivated and wild species. Some diploids grouped according to their geographic origins, among which Musa ornata and IAC-1, and Tjau Lagada and Lidi, while in others no relation was established. There was a trend of clustering among related diploids as: SH3263 and 8694-20; 4279-01 and 9179-03; $1304-06$ and 5854-03; 86B79-10 and 7341-03; 86B79-12 and 0337-02; and 9194-04 and 4154-08.
\end{abstract}

Index terms: Musa, diploids, genetic diversity, hybrids, molecular markers.

\section{Introdução}

A banana é a segunda fruta mais consumida no Brasil, perdendo apenas para a laranja. Em relação ao seu papel social, a cultura é explorada por pequenos produtores rurais, o que permite a fixação de mão-de-obra no campo, uma vez que se constitui em fonte de renda contínua para esses agricultores (Mascarenhas, 1997).

O Brasil é o segundo maior produtor mundial de banana, tendo produzido 7,1 milhões de toneladas em 2006, em uma área aproximada de 500 mil hectares.
A Índia produziu, no mesmo período, 11,7 milhões de toneladas em 400 mil hectares (FAO, 2008). A baixa produtividade brasileira está associada à falta de variedades comerciais que apresentem, concomitantemente, porte baixo, tolerância à seca e ao frio, resistência aos nematóides, boas características pós-colheita, entre elas a resistência ao despencamento do fruto e resistência às pragas e às principais doenças (sigatokas-amarela e negra, mal-do-panamá, moko e algumas viroses) (Silva et al., 2002). 
Normalmente, a produção de banana está baseada em cultivares triplóides, porém, os genótipos diplóides tornam-se importantes, uma vez que são fontes de alelos de resistência/tolerância a fatores bióticos e abióticos (Jenny et al., 1999). Os programas de melhoramento de bananeira têm gerado híbridos tetraplóides promissores, obtidos a partir do cruzamento entre cultivares triplóides e diplóides melhorados ou selvagens, que apresentam características agronômicas de interesse, entre elas: porte reduzido, resistência a pragas e qualidade físicoquímica dos frutos (Silva et al., 2005).

A caracterização agronômica de diplóides e a estimativa da variabilidade genética disponível para o melhoramento são informações úteis, tanto na escolha de genitores para cruzamentos entre genótipos divergentes, visando a explorar a heterose e a desenvolver novos diplóides melhorados, quanto no cruzamento destes com triplóides, a fim de obter novos híbridos tetraplóides de banana.

Vários marcadores moleculares, em especial aqueles associados a métodos baseados em PCR ("polymerase chain reaction"), incluindo AFLP ("amplified fragment lenght polymorphism"), RAPD ("random amplified polymorphic DNA") e microssatélites ou SSR ("simple sequence repeats") têm sido amplamente utilizados na estimativa da variabilidade genética, na escolha de genitores e em estudos filogenéticos em bananeira (Pillay et al., 2001; Souza, 2002; Ude et al., 2002a, 2002b; Creste et al., 2003, 2004; Wan et al., 2005; Jain et al., 2007; Ning et al., 2007; Nsabimana \& Staden, 2007; Ruangsuttapha et al., 2007; Wang et al., 2007). De todas essas técnicas, os microssatélites têm demonstrado ser os mais indicados para bananeira (Ning et al., 2007), em razão de sua elevada reprodutibilidade e facilidade de interpretação.

O objetivo deste trabalho foi estimar a divergência genética entre 38 diplóides de bananeira utilizados pelo programa de melhoramento de banana da Embrapa Mandioca e Fruticultura Tropical, incluindo genótipos melhorados, cultivados e selvagens, por meio de marcadores moleculares microssatélites ou SSR.

\section{Material e Métodos}

Os 38 diplóides empregados na avaliação do polimorfismo incluem diplóides melhorados, cultivados e selvagens. Destes diplóides, 26 foram desenvolvidos pelo programa de melhoramento genético da Embrapa
Mandioca e Fruticultura Tropical e são utilizados como doadores de pólen na obtenção de cultivares tetraplóides. Informações sobre cada genótipo encontram-se na Tabela 1.

Foram utilizados 15 pares de iniciadores, cinco pertencentes à série $\mathrm{Ma}$, desenvolvida por Crouch et al. (1998), cinco pares da série AGMI desenvolvidos por Lagoda et al. (1998), três da série MaOCEN obtidos por Creste et al. (2006), um iniciador (STMS 1) obtido por Kaemmer et al. (1997) e um iniciador (Mb 1-100) descrito por Oriero et al. (2006) (Tabela 2). O DNA genômico foi extraído de folhas jovens, com uso do método CTAB (Doyle \& Doyle, 1990). A avaliação da quantidade e da qualidade do DNA foi realizada pela análise comparativa das amostras em gel de agarose $0,8 \%$, corado com brometo de etídio, e as amostras foram diluídas em água ultrapura e padronizadas em $10 \mathrm{ng} \mu \mathrm{L}^{-1}$.

As reações de amplificação via SSR foram completadas para o volume final de $13 \mu \mathrm{L}$, com: $\mathrm{KCl} 50 \mathrm{mM}$, Tris- $\mathrm{HCl} 10 \mathrm{mM}$ (pH 8,3), $\mathrm{MgCl}_{2} 2,5 \mathrm{mM}$, $100 \mu \mathrm{M}$ de cada um dos dNTPs (dATP, dTTP, dGTP, $\mathrm{dCTP}), 0,2 \mu \mathrm{M}$ de cada iniciador, $50 \mathrm{ng}$ de DNA genômico e uma unidade de Taq DNA polimerase (Pharmacia Biotech, EUA).

As amplificações foram conduzidas em termociclador Perkin Elmer, modelo 9700, utilizando-se o esquema de "touchdown" com ciclo inicial de $3 \mathrm{~min}$ a $94^{\circ} \mathrm{C}$, seguido de $40 \mathrm{~s}$ a $94^{\circ} \mathrm{C}, 40 \mathrm{~s}$ a $55^{\circ} \mathrm{C}$, reduzindo-se um grau a cada

Tabela 1. Natureza e origem de 38 diplóides de bananeira utilizados pelo programa de melhoramento genético na Embrapa Mandioca e Fruticultura Tropical.

\begin{tabular}{lll}
\hline Natureza $^{(1)}$ & Origem & \multicolumn{1}{c}{ Genótipos $^{(2)}$} \\
\hline DM & Bahia & 0116-01, 0323-03, 0337-02, 1304-06, 1318-01, \\
& & 1319-01, 1741-01, 4154-01, 4154-08, 4215-02, \\
& & $4223-06,4252-03,4253-01,4279-02,5854-03$, \\
& 7341-01, 7341-03, 8694-20, 86B79-02, 86B79-10, \\
& & 87A79-01, 8987-01, 9179-03, 9187-01, \\
& & $9187-02,9194-04$ \\
DM & Equador & F2P2 \\
DM & Honduras & SH3263, SH3362 \\
DS & Bahia & TH0301 \\
Cultivar & Costa Rica & Lidi, Tjau Lagada \\
Cultivar & Honduras & Jari Buaya \\
Selvagem & Honduras & Burmanicca \\
Selvagem & Indonésia & Monyet \\
Selvagem & Jamaica & Calcutta \\
Selvagem & São Paulo & Musa ornata, IAC-1 \\
\hline
\end{tabular}

${ }^{(1)} \mathrm{DM}$ : diplóide melhorado; DS: diplóide simples. ${ }^{(2)} \mathrm{Os}$ dois primeiros números ou letras dos diplóides melhorados correspondem ao genitor feminino, os seguintes, ao genitor masculino e os dois últimos, ao número da seleção. 
ciclo, 1 min a $72^{\circ} \mathrm{C}$, num total de 10 ciclos, seguido de 25 ciclos de 40 s a $94^{\circ} \mathrm{C}, 40$ s a $45^{\circ} \mathrm{C}$ e 60 s a $72^{\circ} \mathrm{C}$.

Os fragmentos foram separados em géis de poliacrilamida desnaturante $(6 \%$ poliacrilamida, $8 \mathrm{M}$ de uréia) sob condições padrões, e os produtos da amplificação foram corados com nitrato de prata para visualização dos alelos, utilizando-se o método de Creste et al. (2001).

Os fragmentos amplificados foram avaliados como ausência (0) e presença (1). A similaridade genética entre todos os 38 genótipos foi calculada a partir do coeficiente de Jaccard $\left[s_{i i}=a /(a+b+c)\right]$, em que: a é o número de concordâncias do tipo 11 ; b é o número de discordâncias do tipo 10 ; e c é o número de discordâncias do tipo 01 .

As similaridades genéticas foram utilizadas para fazer o agrupamento dos genótipos pelo método UPGMA ("unweighted pair-group method averages"), por meio do software NTSYS-pc (Rohlf, 2000). Foi calculado o coeficiente de correlação cofenética (CCC) entre a matriz de similaridades genéticas e a matriz dos valores cofenéticos, a fim de verificar a consistência do agrupamento. Esse coeficiente traduz a relação momentoproduto, calculado entre os elementos da matriz original e os da matriz cofenética, resultante da simplificação proporcionada pelo método de agrupamento, depois da construção do dendrograma. Valores de CCC acima de 0,8 indicam boa representatividade entre as distâncias (Bussad et al., 1990).

O método de reamostragens (Bootstrap) foi realizado para verificar se o número de locos (combinações de iniciadores) foi suficiente para determinar com precisão as estimativas de similaridade genética entre os genótipos, utilizando o software GQMol (Cruz \& Shuster, 2004). O programa obtém estimativas de correlação de valores da matriz de distância original com os de outras matrizes de distância, obtidas considerando-se diferentes números de locos SSR. Além disso, o programa ainda disponibiliza dois outros parâmetros: a soma dos quadrados dos desvios, em relação às reamostragens, e um valor de estresse (E), que é indicativo de ajuste entre a matriz original, considerando todos os SSR, e a matriz amostral, por meio da expressão: $\mathrm{E}=\left[\left(\mathrm{d}_{\mathrm{ij}}{ }^{*}-\mathrm{d}_{\mathrm{ij}}\right) / \Sigma \mathrm{d}_{\mathrm{ij}}{ }^{*}\right]^{0,5}$

em que: E é o estresse; $d^{*}{ }_{i j}$ é a distância genética média entre todos os pares de genótipos, estimada para cada reamostragem; $d_{i j}$ é a distância genética média entre todos os pares de genótipos estimada, a partir do total de iniciadores de SSR.

\section{Resultados e Discussão}

O número de alelos obtidos foi 113, com média de 7,53 alelos por iniciador. O maior número de alelos foi identificado nos iniciadores MaOCEN 03 e AGMI 103 (11 alelos) e o menor número no iniciador STMS 7 (3 alelos) (Tabela 2). O número médio de alelos por loco SSR é similar ao obtido em outros estudos realizados com bananeira (Kaemmer et al., 1997; Grapin et al., 1998; Creste et al., 2003, 2004, 2006; Ning et al., 2007).

O conteúdo de informação de polimorfismo (PIC) variou de 0,35 para o iniciador STMS 7 a 0,88 para o iniciador Ma 3-103, com média de 0,77.

Tabela 2. Locos microssatélites SSR, seqüência repetida (F/R - foward/reverse), número de alelos e conteúdo de informação de polimorfismo (PIC).

\begin{tabular}{|c|c|c|c|}
\hline Locos SSR & Repetição (F/R) & Alelos & PIC \\
\hline AGMI 103-103 & cagaatcgctaaccetatcctca/ccetttgegtgeccetaa & 11 & 0,83 \\
\hline AGMI 187-188 & gcaactttggcagcatttt/tgatggactcatgtgtacctactat & 7 & 0,80 \\
\hline AGMI 24-25 & tttgatgtcacaatggtgttcc/taaaggtgggttagcattagg & 9 & 0,85 \\
\hline AGMI 67-68 & ataccttctcccgttcttcttc/tggaaacccaatcattgatc & 9 & 0,81 \\
\hline AGMI 95-96 & acttattccecegcactcaa/actctcgeccatcttcatcc & 4 & 0,69 \\
\hline Ma 2-7 & tgaatcccaagtttggtcaaga/caactcttgtccctcacttca & 5 & 0,76 \\
\hline Ma 1-17 & aggcggggaatcggtaga/ggcgggagacagatggagt & 7 & 0,83 \\
\hline Ma 1-24 & gagcccattaagctgaaca/ccgacagtcaacatacaataca & 7 & 0,81 \\
\hline Ma 1-27 & tgaatcccaatttggtcaag/caaaacactgtccccatctc & 9 & 0,87 \\
\hline Ma 3-103 & tcgectctctttagctctg/tgttggaggatctgagattg & 10 & 0,88 \\
\hline MaOCEN 01 & tctcaggaagggcaatc/ggaccaaagggaaagaaacc & 5 & 0,75 \\
\hline MaOCEN 03 & ggaggaaatggaggtcaaca/ttcgggataggaggaggag & 11 & 0,76 \\
\hline MaOCEN 13 & gctgctattttgtccttggtg/cttgatgctgggaatctgg & 8 & 0,86 \\
\hline $\mathrm{Mb} 1-100$ & tcggctggctaatagaggaa/tctcgagggatggtgaaaga & 8 & 0,78 \\
\hline STMS 7 & aagaaggcacgagggtag/cgaaccaagtgaaatagcg & 3 & 0,35 \\
\hline Total & & 113 & \\
\hline Média & & 7,53 & 0,77 \\
\hline
\end{tabular}


A correlação entre o número de alelos e o PIC foi alta $(\mathrm{r}=0,66, \mathrm{p} \leq 0,005)$, o que indica que iniciadores com maior número de alelos apresentam maior poder discriminatório entre os genótipos avaliados.

$\mathrm{Na}$ análise de reamostragens, 106 alelos foram suficientes para uma estimativa precisa da divergência genética entre os 38 diplóides de bananeira. A correlação entre a matriz com todos os 113 alelos e a matriz com 106 alelos foi de 0,98 , com soma dos quadrados dos desvios $\left(\mathrm{SQ}_{\mathrm{d}}\right)$ de 0,27 e valor de estresse (E) de 0,0475. De acordo com Kruskal (1964), um valor de $\mathrm{E} \leq 0,05$ é indicativo de uma excelente precisão nas estimativas. $\mathrm{Na}$ literatura são encontrados trabalhos em que o número de marcadores SSR, assim como o número de alelos utilizados para genotipar diferentes genótipos de bananeira foram inferiores aos utilizados neste trabalho. Ning et al. (2007) consideraram suficientes 10 SSR para genotipar 50 acessos de bananeira de diferentes origens, tendo encontrado 92 alelos; Creste et al. (2004) utilizaram 9 SSR para genotipar 49 diplóides, a partir de 115 alelos, e Creste et al. (2003) genotiparam 35 cultivares de bananeira com 11 SSR e 67 alelos.

A similaridade genética média entre todos os diplóides foi 0,22, e variou de 0,028 - entre os diplóides 9179-03 e 9194-04 - a 0,48, entre os genótipos Calcutta e 4215-02, o que indica a existência de variabilidade genética entre os genótipos. Creste et al. (2004) avaliaram a diversidade genética entre 49 acessos diplóides do Banco Ativo de Germoplasma de Banana (BAG Banana) da Embrapa, por meio de marcadores SSR, e encontraram uma similaridade genética média de 0,10. Pillay et al. (2001) utilizaram marcadores RAPD para inferir sobre a variabilidade genética disponível entre 31 acessos de banana utilizados na Nigéria. Com base nos resultados, os autores concluíram que a base genética disponível para melhoramento naquele País é estreita. Resultados semelhantes foram encontrados por Ning et al. (2007), com 31 acessos na China, genotipados com RFLP e SSR, e por Ruangsuttapha et al. (2007) com 22 cultivares na Tailândia, genotipados com RAPD.

O dendrograma das similaridades genéticas baseada em SSR, obtido pelo método UPGMA, encontrase na Figura 1. O valor cofenético foi alto $(r=0,61$, $\mathrm{p}<0,0001,10.000$ permutações) e adequado, já que valores de $r \geq 0,56$ são considerados ideais, o que reflete boa concordância com os valores de similaridade genética (Vaz Patto et al., 2004).
Neste trabalho, assumiu-se como ponto de corte no dendrograma a similaridade genética média entre todos os diplóides genotipados com microssatélites $(0,22)$. Com base neste ponto de corte foram formados seis grupos: G1, genótipos 1318-01 e 4154-01; G2, diplóides SH3263, 8694-20, 4223-06 e 0116-01; G3, com 27 genótipos, incluindo diplóides melhorados, cultivados e selvagens; G4, com apenas um diplóide (Jari Buaya); G5, com Musa ornata e IAC-1; e G6, com Monyet e o diplóide melhorado 8987-01 (Figura 1).

Constata-se, por meio do dendrograma, relativa similaridade genética entre os diplóides melhorados utilizados rotineiramente pelo programa de melhoramento da Embrapa. Este fato pode estar associado ao pequeno número de genitores utilizados na obtenção desses híbridos. É possível verificar, também, que não foi possível obter uma perfeita separação entre os genótipos diplóides cultivados, selvagens e melhorados. Isso é decorrente da existência de muitos alelos comuns a esses genótipos e, portanto, aparentados.

Neste trabalho, foi possível observar que alguns diplóides agruparam-se com base em sua origem geográfica, entre eles Musa ornata e IAC-1 (G5) e Tjau Lagada e Lidi (G3), enquanto que em outros, nenhuma relação foi estabelecida. Resultados semelhantes foram obtidos por Grapin et al. (1998); Jenny et al. (1999) e Creste et al. (2001). De acordo com esses autores, a impossibilidade de estabelecer uma correlação entre esses diplóides e sua origem geográfica pode refletir uma intervenção antrópica relativamente recente durante a dispersão desses genótipos. A presença dos diplóides selvagens Burmanicca e Calcutta no G3 justifica-se em razão de ambos serem o mesmo genótipo, apenas com local de coleta diferenciados e sinonímia particular. Musa ornata (seção Rhodochlamys) e Monyet (seção Eumusa) agruparam separadamente, o que concorda com os resultados encontrados por Pillay et al. (2001) que, ao utilizar marcadores AFLP, também observaram nítida separação entre esses diplóides. Os diplóides melhorados desenvolvidos pela Embrapa ficaram dispersos entre cinco dos seis grupos, sendo $85 \%$ desses genótipos no G3 (Figura 1).

Observa-se elevada similaridade genética no G3, em relação aos diplóides melhorados, fato que pode estar associado com o pequeno número de genitores envolvidos na obtenção desses genótipos. 
Foram utilizados 20 diplóides, incluindo cultivares comerciais, selvagens e melhoradas, na obtenção dos 26 diplóides em uso pela Embrapa, e o diplóide Calcutta aparece em $70 \%$ das genealogias (Figura 2). Esse diplóide é amplamente utilizado em vários programas de melhoramento de banana como fonte de alelos para resistência à sigatoka-negra, causada por Mycosphaerella fijiensis (Pillay et al., 2001). Outros diplóides, tais como: Borneo, Heva, Madang, Malaccensis e Tuu Gia aparecem numa freqüência superior a $15 \%$. Seis genótipos contribuíram com grande parte dos alelos presentes nos diplóides melhorados, o que justifica a similaridade genética entre eles.

Houve tendência de agrupamento entre os diplóides aparentados, como: SH3263 e 8694-20, 4279-01 e 9179-03, 1304-06 e 5854-03, 86B79-10 e
7341-03, 86B79-12 e 0337-02, e 9194-04 e 4154-08 (Figuras 1 e 2). Este fato reforça a eficiência dos marcadores SSR em classificar os genótipos segundo sua genealogia. Outros trabalhos têm indicado o uso de microssatélites para alocar genótipos de bananeira segundo sua origem, genealogia ou grupo genômico (Creste et al., 2003, 2004; Jesus et al., 2006).

Atualmente, o programa de melhoramento genético de banana da Embrapa Mandioca e Fruticultura Tropical conta com 99 diplóides melhorados, com resistência genética às principais pragas, incluindo as sigatokas-amarela e negra e o mal-do-panamá, além de características agronômicas desejáveis, tais como: porte reduzido, alta produtividade, tolerância à seca etc. Desta forma, infere-se que a variabilidade genética disponível seja suficiente para o melhoramento

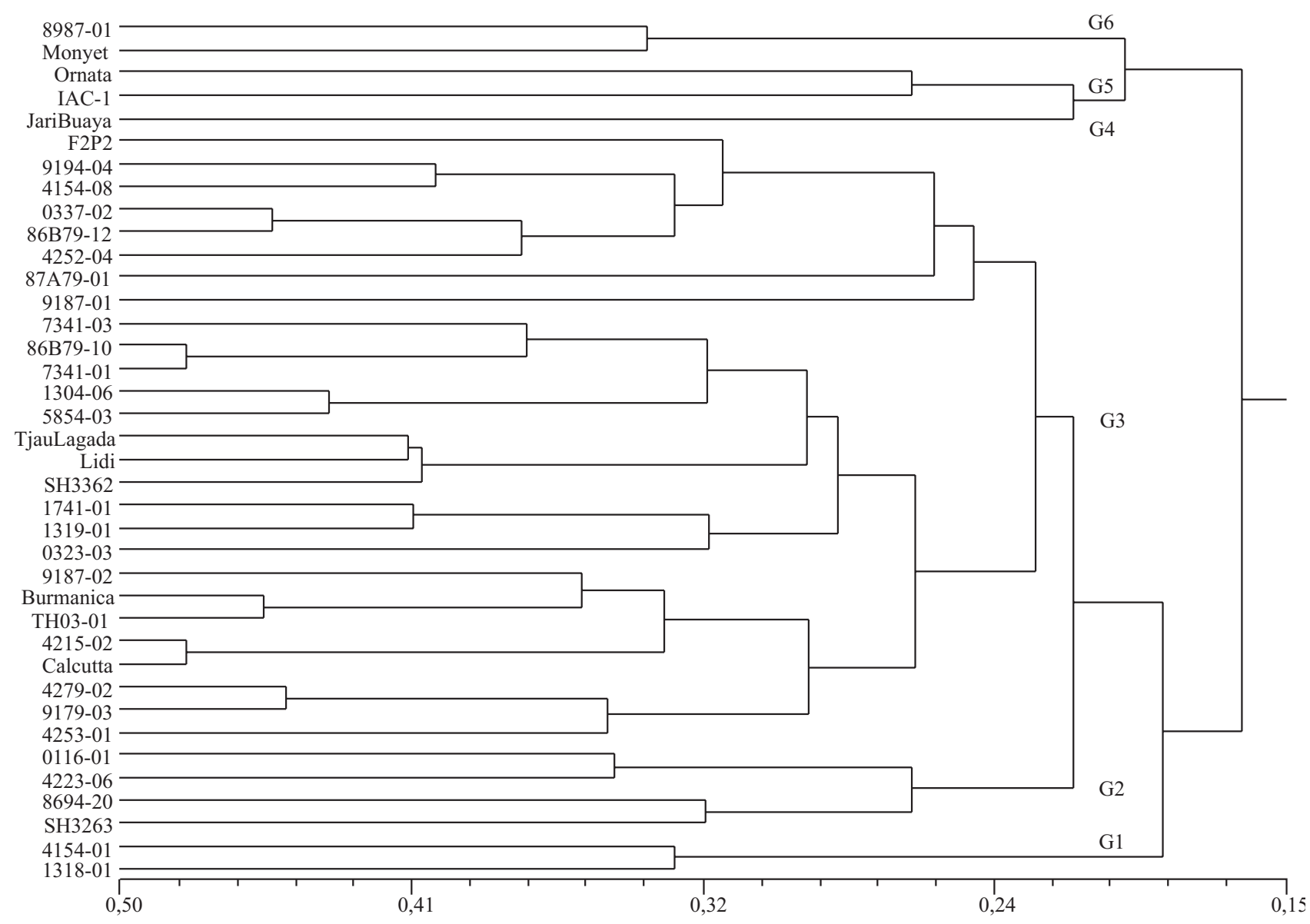

Figura 1. Similaridade genética entre 38 diplóides de bananeira, obtida a partir do coeficiente de Jaccard, com base nos marcadores moleculares microssatélites, com o uso do método UPGMA. 

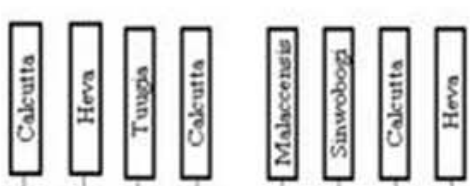

各图产图

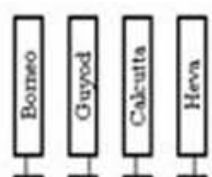

这

问阅回回问阅回圆回

目圆圆圆

圆 圆

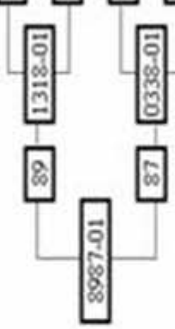

圆圆

调调

周

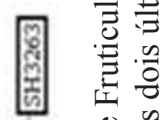

图

固图

园图

固图

目四圆国国

固圆国

윰

图圆圆圆目圆

圆固圆 圆

周圆圆

图图图

啇

鱼 善

圆图

圈图害图

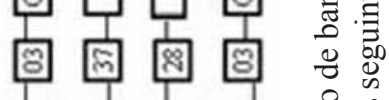

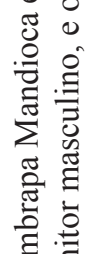

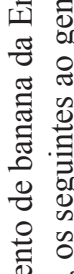

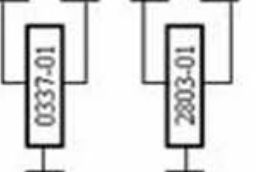

阁图 总

竞.

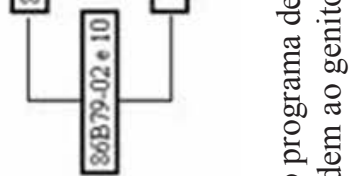

잉 중

을

图图图图图園

圆圆圆固固

圆彭彭 彭

图图

图图圆

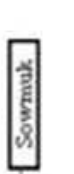

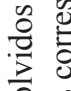

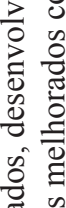

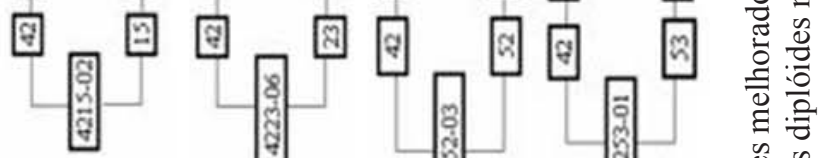

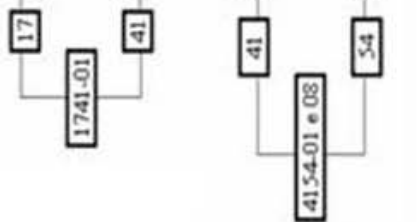

图图图

量

图

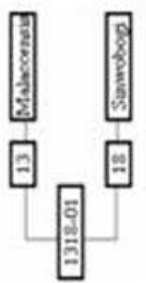

图图图

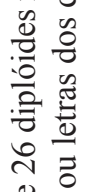

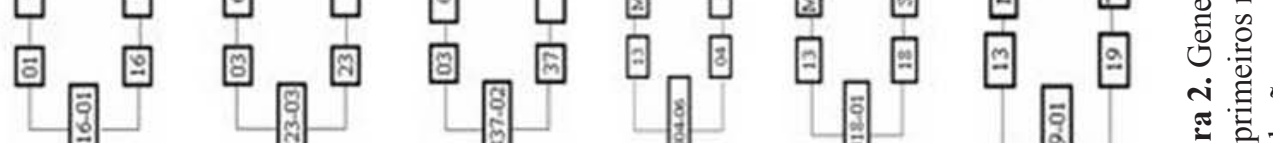

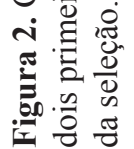


da cultura, uma vez que ganhos genéticos têm sido obtidos ao longo dos anos, o que contribui para o lançamento de cultivares tetraplóides com características agronômicas favoráveis e resistentes às principais pragas e doenças.

Novas combinações parentais podem ser identificadas com base na divergência entre esses diplóides, o que contribui para o desenvolvimento de novos diplóides melhorados, de forma a evitar o afunilamento da base genética e disponibilizar nova variabilidade genética para a seleção.

\section{Conclusões}

1. Existe variabilidade genética suficiente para o desenvolvimento de novos diplóides melhorados com boas características agronômicas.

2. Os marcadores SSR são eficientes para a classificação de genótipos de bananeira segundo sua genealogia.

3. O número de marcadores SSR é suficiente para estimativa precisa da variabilidade genética entre os 38 diplóides.

\section{Referências}

BUSSAD, W. de O.; MIAZAKI, E.S.; ANDRADE, D.F. Introdução à análise de agrupamentos. São Paulo: ABE, 1990. $105 \mathrm{p}$.

CRESTE, S.; BENATTI, T.R.; ORSI, M.R.; RISTERUCCI, A.M.; FIGUEIRA, A. Isolation and characterization of microsatellite loci from a commercial cultivar of Musa acuminata. Molecular Ecology Notes, v.6, p.303-306, 2006.

CRESTE, S.; TULMANN NETO, A.; FIGUEIRA, A. Detection of single sequence repeats polymorphisms in denaturing polyacrylamide sequencing gel by silver staining. Plant Molecular Biology Reporter, v.19, p.299-306, 2001.

CRESTE, S.; TULMANN NETO, A.; SILVA, S. de O.; FIGUEIRA, A. Genetic characterization of banana cultivars (Musa spp.) from Brazil using microsatellite markers. Euphytica, v.132, p.259-268, 2003.

CRESTE, S.; TULMANN NETO, A.; VENCOVSKY, R.; SILVA, S. de O.; FIGUEIRA, A. Genetic diversity of Musa diploid and triploid accessions from the Brazilian banana breeding program estimated by microsatellite markers. Genetic Resources and Crop Evolution, v.51, p.723-733, 2004.

CROUCH, H.K.; CROUCH, J.H.; JARRET, R.L.; CREGAN, P.B.; ORTIZ, R. Segregation at microsatellite loci in haploid and diploid gametes of Musa. Crop Science, v.38, p.211-217, 1998.

CRUZ, C.D.; SCHUSTER, I. GQMOL - Aplicativo computacional para análise de dados moleculares e de suas associações com caracteres quantitativos: versão 2.1. Viçosa: UFV, 2004.
DOYLE, J.J.; DOYLE, J.L. Isolation of plant DNA from fresh tissue. Focus, v.12, p.13-15, 1990.

FAO. Food and Agriculture Organization of the United Nations. FaoStat. Disponível em: <http://faostat.fao.org/ site $/ 567 /$ DesktopDefault.aspx?PageID $=567>$. Acesso em: 10 fev. 2008.

GRAPIN, A.; NOYER, J.L.; CARREEL, F.; DAMBIER, D.; BAURENS, F.C.; LANAUD, C.; LAGODA, P.J.L. Diploid Musa acuminata genetic diversity assayed with sequence-tagged microsatellite sites. Electrophoresis, v.19, p.1374-1380, 1998.

JAIN, P.K.; SAINI, M.L.; PATHAK, H.; GUPTA, V.K. Analysis of genetic variation in different banana (Musa species) variety using random amplified polymorphic DNAs (RAPDs). African Journal of Biotechnology, v.6, p.1987-1989, 2007.

JENNY, C.F.; CARREEL, F.; TOMEKPE, K.; PERRIER, X.; DUBOIS, C.; HORRY, J.P.; MONTCEL, H.T. Les bananiers. In: HAMON, P.; SEGUIN, M.; PERRIER, X.; GLAZMAN, J.C. (Ed). Divesité génétique des plantes tropicales. Montpellier: Cirad, 1999. p.113-139.

JESUS, O.N. de; CÂMARA, T.R.; FERREIRA, C.F.; SILVA, S. de O. e; PESTANA, K.N.; SOARES, T.L. Diferenciação molecular de cultivares elites de bananeira. Pesquisa Agropecuária Brasileira, v.41, p.1739-1748, 2006.

KAEMMER, D.; FISCHER, D.; JARRET, R.L.; BAURENS, F.C.; GRAPIN, A.; DAMBIER, D.; NOYER, J.L.; LANAUD, C.; KAHL, G.; LAGODA, P.J.L. Molecular breeding in genus Musa: a strong case for STMS marker technology. Euphytica, v.96, p.49-63, 1997.

KRUSKAL, J.B. Multidimensional scaling by optimizing goodness of fit to a nonmetric hypothesis. Psychometrika, v.29, p.1-27, 1964.

LAGODA, P.J.L.; NOYER, J.L.; DAMBIER, D.; BAURENS, F.C.; GRAPIN, A.; LANAUD, C. Sequence tagged microsatellite site (STMS) markers in the Musaceae. Molecular Ecology, v.7, p.659-663, 1998.

MASCARENHAS, G. Análise do mercado brasileiro de banana. Preços Agrícolas, v.134, p.4-12, 1997.

NING, S.P.; XU, L.B.; LU, Y.; HUANG, B.Z.; GE, X.J. Genome composition and genetic diversity of Musa germplasm from China revealed by PCR-RFLP and SSR markers. Scientia Horticulturae, v.114, p.281-288, 2007.

NSABIMANA, A.; STADEN, J. van. Assessment of genetic diversity of Highland bananas from the National Banana Germplasm Collection at Rubona, Rwanda using RAPD markers. Scientia Horticulturae, v.113, p.293-299, 2007.

ORIERO, C.E.; ODUNOLA, O.A.; LOKKO, Y.; INGELBRECHT, I. Analysis of B-genome derived simple sequence repeat (SSR) markers in Musa spp. African Journal of Biotechnology, v.5, p.126-128, 2006.

PILLAY, M.; OGUNDIWIN, E.; NWAKANMA, D.C.; UDE, G.; TENKOUANO, A. Analysis of genetic diversity and relationships in East African banana germoplasm. Theoretical and Applied Genetics, v.102, p.965-970, 2001. 
ROHLF, F.J. NTSYS-PC: numerical taxonomy and multivariate analysis system. New York: Exeter Software, 2000. 38p. (Version 2.1).

RUANGSUTTAPHA, S.; EIMERT, K.; SCHRÖDER, M.B.; SILAYOI, B.; DENDUANGBORIPANT, J.; KANCHANAPOOM, K. Molecular phylogeny of banana cultivars from Thailand based on HAT-RAPD markers. Genetic Resources and Crop Evolution, v.54, p.1565-1572, 2007.

SILVA, S. de O. e; ALVES, E.J.; LIMA, M.B.; SILVEIRA, J.R.S. Bananeira. In: BRUCKNER, C.H. (Ed.). Melhoramento de fruteiras tropicais. Viçosa: UFV, 2002. p.101-157.

SILVA, S. de O. e; MORAIS, L.S.; SANTOS-SEREJO, J.A. Melhoramento genético de bananeira para resistência a doenças. In: ROMÃO, R.L.; RAMOS, S.R.R. (Ed.). Recursos genéticos vegetais no Estado da Bahia. Feira de Santana: UEFS, 2005. p.49-67.

SOUZA, S.A.C.D. de. Avaliação da variabilidade genética em Musa spp. utilizando marcadores microssatélites. 2002. 86p. Tese (Doutorado) - Universidade de São Paulo, Piracicaba.
UDE, G.; PILLAY, M.; NWAKANMA, D.C.; TENKOUANO, A. Analysis of genetic diversity and sectional relationships in Musa using AFLP markers. Theoretical and Applied Genetics, v.104, p.1239-1245, 2002a.

UDE, G.; PILLAY, M.; NWAKANMA, D.C.; TENKOUANO, A. Genetic diversity in Musa acuminata Colla and Musa balbisiana Colla and some of their natural hybrids using AFLP markers. Theoretical and Applied Genetics, v.104, p.1246-1252, $2002 \mathrm{~b}$.

VAZ PATTO, M.C.; SATOVIC, Z.; PÊGO, S.; FEVEREIRO, P. Assessing the genetic diversity of Portuguese maize germplasm using microsatellite markers. Euphytica, v.137, p.63-72, 2004.

WAN, Y.; WATANABE, J.A.; YI, S.S.; HTAIK, T.; WIN, K.; YAMANAKA, S.; NAKAMURA, I.; WATANABE, K.N. Assessment of genetic diversity among the major Myanmar banana landraces. Breeding Science, v.55, p.365-369, 2005.

WANG, X.L.; CHIANG, T.Y.; ROUX, N.; HAO, G.; GE, X.J. Genetic diversity of wild banana (Musa balbisiana Colla) in china as revealed by AFLP markers. Genetic Resources and Crop Evolution, v.54, p.1125-1132, 2007.

Recebido em 28 de fevereiro de 2008 e aprovado em 31 de julho de 2008 